\title{
Historical Perception of Korean Medical Education
}

\section{Ducksun Ahn}

Department of Plastic and Reconstructive Surgery, Korea University Medical College, Seoul, Korea

\section{의학교육의 역사적 인식}

고려대학교 의과대학 성형외과학교실

안덕선

우리나라에서 의학교육에 대한 관심이 본격적으로 고조되기 시작한 것은 1990년 이후 한국의학교육학회와 의과대학학장 협의회의 단체적 기능이 활성화되면서부터라고 하여도 무방 할 것 같다. 해방 이후 혼돈과 성장의 시절을 거치면서 우리의 의학교육은 스스로에 대한 정체성을 살펴볼 물리적, 정신적 여유가 없었다. 그러나 6.25 전쟁 중의 혼란과 어려움 속에서 도 전문의 제도를 논의하고 정착시킨 것을 보면 의료와 교육 에 대한 관심은 상존하였던 것 같기도 하다. 그러나 거칠었던 역사적 세월 속에서 신설된 전문의 제도는 수련 과목의 설정 과 수련 기간의 명시에만 머물렀을 뿐 전문의 제도 속에 반드 시 병행되어야 하는 전공의 교육의 변화까지 담아내지는 못하 였다. 1970 년대 의료보험제도의 도입도 의료에 대한 강압적 정책의 결과였고, 의료환경 변화에 따른 의사양성교육은 강압 적 제도 정착에 대한 반발로 관심의 대상이 되지 못하였다.

아시아의 국가별로 의학교육의 특성을 살펴보면 불행하였 던 과거사가 그대로 나타난다. 동남아시아 국가의 경우 영국 의 식민지였던 과거가 오늘날의 교육적 특성으로 잘 나타나고 있고, 한국과 대만 그리고 일본은 독일의 국가의료를 도입하
였던 일본의 그림자가 그대로 반영되어 있다. 우리나라 의과 대학의 예과와 본과 형태를 갖추고 있는 기본의학교육과정은 이제 지구상에서 찾아보기가 매우 힘들다. 일본조차도 예과교 육의 어려움과 비효율성을 자각하고 예과와 본과의 2 단계 교 육을 포기하고 6년제 통합교육을 선택하였다. 그러나 경계선 만 지워졌지 실상 교육내용이 근본적으로 잘 바뀐 것은 아니 다. 아시아에서 의학교육의 강국은 홍콩, 싱가포르 등 구 영국 의 교육제도에서 성장했던 나라들이다. 최근 말레이시아의 약 진을 보면 이런 사실이 더욱 눈에 보인다. 영국 식민지나 영연 방국가였던 아시아 국가의 특징은 세계적인 교육의 흐름에 대 한 이해가 높고, 식민지의 경험을 통해 현재까지도 교육에 있 어 영국문화와 계속적으로 교류하고 있다는 사실이다. 우리나 라의 식민지 형태는 악성식민(malignant colonization) 정책 이었던데 반하여 영국의 식민정책은 언젠가 식민주민이 스스 로 독립하여 근대국가를 형성할 수 있도록 하였다는 계몽식민 (enlightenment colonization)이었다는 차이점을 보인다. 아 시아의 영국식민지는 독립 후에도 영국과의 관계를 잘 유지하 여 현대적 민주사회와 전문직의 발달을 도모하였다. 실상 2차
Received: February 9, 2011 • Revised: February 12, 2011 • Accepted: February 15, 2011 Corresponding Author: Ducksun Ahn

Department of Plastic and Reconstructive Surgery, Korea University Medical College, 126-1 Anam-dong 5-ga, Seongbuk-gu,, Seoul 136-705, Korea

Tel: +82.2.920.5342 Fax: +82.2.920.6198 email: dsahn@korea.ac.kr
Korean J Med Educ 2011 Jun; 23(2): 79-81. doi: $10.3946 /$ kjme.2011.23.2.79. pISSN: 2005-727X eISSN: 2005-7288

(C) The Korean Society of Medical Education. All rights reserved. This is an open-access article distributed under the terms of the Creative Commons Attribution Non-Commercial License (http:// creativecommons.org/licenses/by-nc/3.0/), which permits unrestricted non-commercial use, distribution, and reproduction in any medium, provided the original work is properly cited. 
세계대전 이전의 아시아에 대한 영향력은 영국이 월등히 앞서 보인다. 이런 전문직 성장과정은 전문직 단체의 기능을 일찍 이해하고 전문직이 갖추어야 할 기관전문직업성(organizational professionalism)의 형성을 가능하게 하였다. 동아시 아 특히 한, 중, 일에서 전문직의 역사는 존재하지 않았었다. 이것은 식자층인 사층(socra-aristocrat)이 전문직 역할을 담 당했었던 유교의 독특한 문화형태에서 비롯된 것으로 보인다. 유교적 사 $( \pm)$ 층의 가족적 범위의 사고는 사회계약적 형태의 근대적 전문직 사고를 발달시키지 못하였다. 유럽의 전문직의 역사가 근대로 진입하면서 자율규제나 사회적 계약에 대한 사 고가 발달한 반면 의, 법으로 대변되는 우리의 전문직은 아직 도 거시적 사고의 발달장애를 보여준다.

의학교육의 발달을 위하여 우리의 의학 교육계도 부단한 노력을 하여 왔다. 1990년대에는 교육방법론과 평가에 대한 신개념 도입이 활발하였고 그 결과로 의사국가시험에서 실기 시험도 실시하게 되었다. 그러나 소규모 그룹 위주의 수업은 아직 이론에 그치거나 지지부진한 상태를 면하지 못하고 있 다. 2000년대에는 의학교육 방법론에서 벗어나 우리의 의학 교육의 정체성에 관한 논의가 시작되었다. 1980년대 교육학 자 이성호는 일제가 전수한 서양의 학문은 정통성을 상실한 변질된 것임을 간파하였다. 한영림의 분석에 의하면 일제는 고등교육에서 조선인의 이성적 진보를 이끌어낼 수 있는 인 문학이나 고급과학기술은 정책적으로 삭제하였다고 밝히고 있다. 일제가 우리에게 물려준 식민지형 고등교육제도에서 의학은 자연과학으로 굳어졌다. 이런 과학 중심의 의학은 일 제가 끝나고 현재에 이르기까지 계속 진행 중에 있다. 이제는 서양의학의 발전이 인문학에서 출발한다는 사실과 자연과학 의 인간적 적용을 위하여 인문학이 필요하다는 것도 깨닫게 되었다. 우리의 고등교육이 식민교육에서 출발하는 것은 부 인할 수 없다. 그러나 아직도 식민문화유산이 고등교육에 스 며들어 있는 현재의 교육을 마치 우리의 고유한 것으로 생각 하게 만드는 함정 역시 우리가 갖고 있는 정치, 사회, 문화적 배경에 대한 이해를 통해 반드시 극복하여야 한다. 식민의학 교육 유산의 최대 약점은 의학에 대한 시선이 아직도 자연과 학적으로 국한된다는 것이다. 의학은 정치, 사회, 경제, 문화 를 총망라하는 통합적이고 종합적인 학문이다. 자연과학적 의학교육은 우리의 의료를 과학적 의학(scientific medicine)
에 국한시키고 사회적 실천(social practice)으로 이행시키지 못하게끔 하는 원인이 되고 있다. 의학에 관한 종합적인 관점 의 상실은 의료가 갖는 사회적, 문화적, 역사적 배경에 대한 이해부족의 현상을 초래하고 의료를 중심으로 펼쳐지는 인간, 가족, 사회와는 거리를 두고 있다. 의료계 일각에서는 1 차 진 료 강화와 활성화를 주장하지만 실제로 우리사회에서 1차 진 료를 정확히 이해하는 것은 매우 힘들어 보인다. 1 차 진료의 활성화는 의학의 과학적이고 기술적인 문제가 아닌 사회의 문화적, 제도적 그리고 역사적인 문화자산(culture capital)의 형성을 요구한다. 같은 이치로 자연과학 중심의 의학교육은 의료윤리나 전문직 단체의 기관전문직업성의 발달장애로 나 타나기도 한다. 과학적 의학 자체와 의과학 위주 교육방식이 1 차 진료의 본질적 의미와 사회적 실천이라는 개념의 수용을 방해하는 장애요인이기 때문이다.

의료는 곧 문화이다. 물론 의사를 양성하는 의과학의 내용 은 세계 공통적이다. 그러나 의료의 양상은 사회적, 문화적, 역사적 환경에 따라 매우 다르게 표현된다. 현재 전문의 위주 의 고도로 전문화된 우리의 의료문화가 어디서 기원하였는가 를 곰곰이 생각해보고 성찰적인 입장에서 접근할 필요가 있 다. 우리나라의 의사의 역할은 과학적 의학의 수준에서 '간헐 적 전문 기술제공자로 표현된다. 또한 우리나라에서 1 차 진 료는 존재하지 않는 것처럼 보인다. 타국과의 의료에 대한 비 교 문화적 방법을 도입하여 보면 우리의 의료에 대한 모습을 더욱 정확히 파악할 수 있다. 임상교육의 취약점을 둘러싼 우 리와 일본, 대만의 이야기는 놀랄 만큼 비슷하다. 그리고 의료 의 형태와 속성도 닮은 점이 매우 많다. 대만과 일본의 의학교 육에 관한 영문문헌을 검토하여 보면 마치 우리나라의 의학 교육의 문제를 잘 기술하고 대변한 것 같다.

우리의 의료문화를 비판적 입장에서 접근하면 의학교육의 나아갈 방향도 제시된다. 비판적 입장의 시각을 갖추기 위해 먼저 할 일은 의학교육에 대한 역사적 인식이다. 아직도 우리 나라 의학교육의 많은 부분은 일제가 물려준 식민지형태의 교육을 답습하고 있다. 졸업 후 교육의 특성도 가족적 단위의 의국문화이다. 가족적 교육의 특징이 좋고 따뜻한 점도 있다. 그러나 의료가 갖는 사회성과 전문직이 갖는 보편적 가치의 창출이라는 입장에서 보면 이제 가족적 교육은 탈피할 때가 되었다. 또한 우리가 갖는 군사적 문화의 유산, 비민주적 형태 
의 교육을 탈피하기 위해서는 의학교육이 세계적 변화의 물 결과 동시성을 추구하면서 동시에 우리의 과거를 반추하는 양방향적인 노력을 경주해야 한다. 역사의 공부는 과거의 반 성과 건설적 미래의 설계에 있다. 우리 의학교육의 미래는 최 신 지견의 도입으로 해결되지 않는다. 최신 지견이 우리 토양 에서 생존하기 위해서는 최신 지견이 갖고 있는 역사적, 문화 적 전통에 대한 이해가 같이 되어야 하고 우리의 토양에서 정 착되기 위한 우리의 역사적, 문화적 전통에 대한 이해도 동시 에 이루어져야 하기 때문이다. 이런 사실은 흔히 의사소통 교 육에서 환자와 의사의 공감대 형성을 강조하는 것과 동일한 이치다. 우리 의학교육이 걸어온 지평과 최신 지견이 탄생된 사회문화적 배경이 같이 만나 공유점이 발견되지 않는 한 새 로운 경향과 지견은 탁상공론이나 '의학교육학주의'로 변질
될 수밖에 없고 의학교육의 변화를 이끌어내는 원동력이 되 지 못한다. 의학교육자가 철없는 이상론자나 시대착오적 이 론가로 인식되지 않기 위하여 의학교육 참여자 모두가 공감 을 시작할 수 있는 공통관심의 원점을 필요로 한다. 우리에게 100 년 정도 되는 의학교육의 역사적 인식은 의학교육의 발전 을 실천으로 이끌 수 있는 가장 좋은 전략적 지점이 될 수 있 을 것이다.

Acknowledgements: None.

Funding: None.

Conflicts of interest: None. 